\title{
ANÁLISE DAS PROPRIEDADES DO CONCRETO UTILIZANDO RESÍDUOS DA CONSTRUÇÃO CIVIL
}

\section{ANALYSIS OF CONCRETE PROPERTIES USING CIVIL CONSTRUCTION RESIDUES}

\section{Leandro Miranda dos Santos'; Larissa Queiroz Minillo'; Daniele Araujo Altran²; Filipe Bittencourt Figueiredo $^{2}$}

\author{
${ }^{1}$ Univesidade do Oeste Paulista - UNOESTE, Curso de Engenharia Civil, Presidente \\ Prudente, SP. \\ E-mail: Imiranda@hotmail.com.br \\ ${ }^{2}$ Universidade Federal da Grande Dourados - UFGD, Faculdade de Engenharia, \\ Dourados, MS.
}

RESUMO - Os impactos causados pelos RCC vêm crescendo exponencialmente a cada ano, que por esta razão, impõem a criação de medidas para mitigar e minimizar tal poluição ao meio ambiente. O propósito desta pesquisa foi avaliar as propriedades físico-mecânicas do concreto a partir da substituição gradual do agregado miúdo natural pelo agregado reciclado. Foi confeccionado o concreto reciclado com substituições de 20, 40, 60, 80 e 100\% de agregado reciclado, cujo fator água/cimento adotado é de 0,7 . Corpos de prova foram produzidos e após o tempo de cura de 7, 14 e 28 dias foram rompidos. Pôde-se analisar que com o aumento da substituição de agregado reciclado a resistência do concreto aumentou, porém não atingindo a resistência modera de 20Mpa Portanto pode-se concluir, que é viável a utilização de agregado reciclado na fabricação de concreto de baixa resistência.

Palavras-chave: Construção Civil; Concreto; Resíduos de construção civil; Meio Ambiente; Agregados reciclados.

ABSTRACT - The impacts caused by RCCs are growing exponentially each year, which is why it is necessary to create measures to mitigate and minimize such an effect. The purpose of this research was to evaluate the physicalmechanical properties of the concrete from the gradual replacement of the natural fine aggregate by the recycled aggregate. The recycled concrete was made with substitutions of $20,40,60,80$ and $100 \%$ of recycled aggregate, whose water / cement factor was 0.7 . Test specimens were produced and after the cure time of 7,14 and 28 days the specimens were ruptured. It was possible to analyze that with the increase of the recycled aggregate substitution, the concrete strength increased, but did not reach an average resistance of $20 \mathrm{Mpa}$. Therefore it is possible to conclude that the use of recycled aggregate in the manufacture of low resistance concrete is.

Keywords: Civil Construction; Concrete; Construction Waste; Environment; Recycled Aggregates. 


\section{INTRODUÇÃO}

Num mundo cada vez mais populoso e globalizado é de extrema importância considerar cada vez mais as consequências que o consumo desenfreado e inconsequente de recursos naturais causam ao meio ambiente. Por esta ordem, é evidente que mudanças na postura em relação à conscientização ambiental tenham ocorrido mundialmente.

O Brasil produz imensa quantidade de resíduos todos os anos. Segundo Angulo (2004) a composição média de resíduos de construção civil (RCC) gerado, em porcentagem, no Brasil é aproximadamente $63 \%$ de argamassa, $29 \%$ de concreto e blocos e 7\% de cerâmicas e revestimentos.

De acordo com Leite (2001) a reciclagem é a melhor alternativa para reduzir o impacto que o ambiente pode sofrer com o consumo de matéria prima e geração descontrolada de resíduos, pois além de minimizar os problemas com o gerenciamento dos resíduos dos municípios, promove crescimento da vida útil dos aterros, e diminui os pontos clandestinos de descarte.

Ainda segundo Leite (2001) muitos tipos de resíduos já estão sendo reciclados, porém sua aplicação ainda é restrita, mas algumas utilizações já são bem difundidas, tais como a utilização em sub-base de pavimentos e produção de concretos sem fins estruturais. Utilizar resíduos da construção civil na fabricação de concretos é essencialmente importante, uma vez que o mesmo é produzido em larga escala no mundo, e incorporar agregado reciclado ao concreto é uma das melhores e mais eficientes formas de gerenciamento de resíduos de construção e demolição.

Este trabalho tem como objetivo analisar as propriedades do concreto de resistência moderada (20MPa) feito a partir de substituições parcial e total de agregado miúdo natural por RCC.

\section{METODOLOGIA}

O presente trabalho se baseou no método indutivo, pois trata se de um método que se inicia com a "observação de fatos ou fenômenos, cujas causas desejamos conhecer" (FREITAS, 2013, p29). Para descobrir as características do concreto reciclado fresco e em seu estado endurecido, foi-se necessário a análise de suas propriedades através dos ensaios de consistência (ABNT NBR 67:1998), resistência a compressão (ABNT NBR 5739:2007) e absorção por capilaridade (ABNT NBR 9779:1995).

\subsection{Traço do concreto e moldagem dos corpos de prova}

Os materiais utilizados foram: areia lavada natural, cimento Portland comum CP I, $\mathrm{RCC}$, água e brita variando seu diâmetro de $4,9 \mathrm{~mm}$ á $19 \mathrm{~mm}$.

O traço utilizado neste trabalho é o apresentado por Silva (1975) no seu livro Manual de traços de concreto, onde o mesmos orientava para se obter um concreto de $20 \mathrm{MPa}$ com o fator a/c (água/cimento) é $0,7.0$ concreto reciclado foi-se realizado adotando substituição de 20 em $20 \%$ de agregado reciclado ao traço. Obteve-se então 4 amostras de concreto com 40, $50,60,80$ e $100 \%$ de agregado reciclado.

Segundo Rossignolo (2009) recomenda-se a pré-saturação em agregados com alta capacidade de absorção de água para se evitar prejuízos da trabalhabilidade do concreto no estado fresco, alteração no fator água cimento da mistura de concreto e também evitar a formação de bolhas de ar ao redor do agregado. Portanto foi necessário a pré-saturação de $6,7 \%$ de água, 10 minutos antes da confecção do concreto para que o mesmo não apresenta-se variação em sua consistência e até mesmo nas característica em seu estado endurecido.

\subsection{Analise das propriedades do concreto.}

Foi-se analisado inicialmente a consistência do concreto através do ensaio abatimento do tronco de cone, que é regido pela ABNT NBR NM 67 :1998. O enchimento de concreto no molde foi realizado em três camadas, cada uma com aproximadamente um terço da altura. Cada camada foi compactada com 25 golpes da haste de socamento. Após completar a última camada, levantou -se cuidadosamente o molde na direção vertical. Imediatamente após a retirada do molde, mediu-se o abatimento do concreto, determinando-se a consistência do concreto fresco.

Após este procedimento foi realizado a modelagem dos corpos de prova para serem rompidos depois de 7, 14 e 27 dias de cura em estufa.

O ensaio de compressão foi realizado por funcionários do laboratório de acordo com a 
ABNT NBR 5739: 2007. Os valores de resistência a compressão foram obtidos e analisados.

Com 28 dias de cura, separou-se um corpo de prova de cada substituição para realizar o ensaio de absorção por capilaridade de acordo com ABNT NBR 9779: 1995. Incialmente foi-se necessário a colocação das amostras em uma estufa com temperatura de $105^{\circ} \mathrm{C}$ a $110^{\circ} \mathrm{C}$, durante 24 horas, para retirar toda umidade interna e externa do concreto. Em seguida foram colocados em uma bandeja metálica em contanto com a água durante 72 horas, onde foram monitorados e analisados a absorção dos corpos de prova.

\section{RESULTADOS}

\subsection{Ensaio do tronco de cone (slump test)}

A Tabela 1 apresenta os valores de leitura obtidos do ensaio.

Tabela 1. Valores do abatimento do tronco de cone (Slump).

\begin{tabular}{c|c}
\hline Substituição & Slump (cm) \\
\hline Piloto & 20 \\
\hline $40 \%$ A.R & 15 \\
\hline $50 \%$ A.R & 7,5 \\
\hline $60 \%$ A.R & 6,5 \\
\hline $100 \%$ A.R & 5,5 \\
\hline
\end{tabular}

Fonte: Os autores.

\subsection{Ensaio de compressão}

A Gráfico 1 apresenta os valores médios da resistência à compressão do concreto em $\mathrm{MPa}$ e os respectivos valores de substituição do agregado reciclado.

Gráfico 1. Resistência à compressão (MPa).

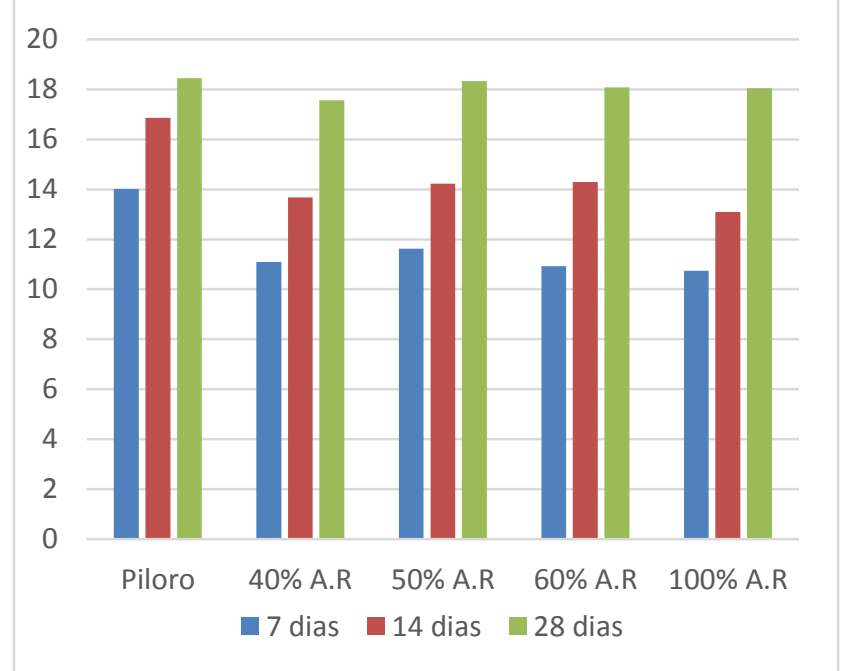

Fonte: Os autores.

\subsection{Absorção do concreto por capilaridade}

A Tabela 2 apresenta os valores obtidos do ensaio.

Tabela 2. Ensaio de absorção de água por capilaridade

\begin{tabular}{c|c|c}
$\begin{array}{c}\text { Corpo de } \\
\text { Prova }\end{array}$ & $\begin{array}{c}\text { Água capilar } \\
\text { 3horas } \\
\left(\mathrm{g} / \mathrm{cm}^{3}\right)\end{array}$ & $\begin{array}{c}\text { Água capilar } \\
72 \text { horas } \\
\left(\mathrm{g} / \mathrm{cm}^{3}\right)\end{array}$ \\
\hline Piloto & 0,17 & 0,94 \\
\hline $40 \%$ A.R & 0,20 & 1,18 \\
\hline $50 \%$ A.R & 0,28 & 1,29 \\
\hline $60 \%$ A.R & 0,33 & 1,27 \\
\hline $80 \%$ A.R & 0,45 & 1,75 \\
\hline $100 \%$ A.R & 0,50 & 1,80 \\
\hline
\end{tabular}

Fonte: Os autores.

\section{DISCUSSÃO}

\subsection{Ensaio de abatimento do tronco cone}

Verifica-se que quando aumenta-se a quantidade de agregado reciclado à mistura, ocorre aumento na consistência, pois segundo Malta, Silva e Gonçalves (2013) os grãos do agregado reciclado proporcionam uma mistura com maior dificuldade de escoamento. Isto ocorre, provavelmente, devido à maior tensão cisalhante entre os grãos, apesar de muitas vezes apresentarem moldabilidade. Percebe-se que o piloto apresentou maior trabalhabilidade, devido ao fator água/cimento e colocação de material na betoneira. Observa-se que com o aumento progressivo da substituição de agregado reciclado obteve-se uma redução no abatimento do concreto. Segundo Neville (1997) a trabalhabilidade em relação ao abatimento de 80 a $160 \mathrm{~mm}$ é muito alta. Por isso, o concreto piloto apresentando $20 \mathrm{~cm}$ de abatimento enquadrouse como muito trabalhável. Já os concretos feitos a partir de agregado reciclados apresentaram menor abatimento. A substituição com $40 \%$ de agregado reciclado apresentou alta trabalhabilidade; $50 \%$ e $60 \%$ de agregado reciclado, média trabalhabilidade. E o concreto feito $100 \%$ com agregado miúdo reciclado apresentou $5,5 \mathrm{~cm}$ de abatimento, isto é, média trabalhabilidade.

\subsection{Ensaio de compressão}

Com o objetivo de estudar as propriedades mecânicas do concreto no estado endurecido, foram ensaiadas amostras do mesmo, para um único traço, com substituições progressivas na quantidade de agregado 
reciclado. Através destes, foi possível investigar a influência do agregado miúdo reciclado nas propriedades do concreto. Diante dos resultados encontrados e sabendo que para todos os traços foi mantida a relação água/cimento de 0,7 , observa-se que não houve dispersão tão grande da resistência à compressão do concreto até o sétimo dia.

Para os valores obtidos com 14 dias de cura, observa-se que a resistência a compressão sofre diminuição a partir dos $60 \%$ de agregado reciclado, isso ocorre devido ao aumento da porcentagem de agregados reciclados na mistura.

Segundo Angulo (2004), ao se analisar os agregados reciclados e os naturais, o agregado reciclado apresenta elevada porosidade e absorção. Esta maior capacidade de absorção faz com que o teor de água inicial presente no agregado e as condições de preparação do concreto tenham uma grande influência nas propriedades do concreto. Assim, acredita-se que tais propriedades como porosidade e absorção foram primordiais para que as resistências finais do concreto tanto para as substituições e o piloto ficarem equiparadas.

De acordo com Malta, et al. (2013), o agregado reciclado devido sua elevada porosidade apresenta maior absorção de água, e isso implica na redução da relação água cimento, que pode resultar no aumento da resistência do concreto.

Pode-se analisar que o aumento na substituição de agregado reciclado miúdo na mistura do concreto proporcionou aumento na resistência do mesmo. Leite (2001) diz que talvez o aumento da resistência se dê pelo fato do agregado reciclado apresentar maior rugosidade, o que contribui para melhorar a aderência, ter granulometria mais contínua e maior teor de pulverulentos, que diminuem a segregação e contribuem para o efeito de empacotamento e fechamento de vazios. Após 28 dias de cura a resistência do concreto reciclado não ultrapassou a resistência do concreto piloto, todavia apresentou valores bem próximos.

\subsection{Ensaio de absorção por capilaridade}

Neste ensaio foi obtida a quantidade de água retida nos poros e nos condutos capilares do concreto. Os valores de absorção vão proporcionar a análise de porosidade e durabilidade do concreto em seu aspecto endurecido. Pode-se analisar que conforme se aumenta a substituição de agregado reciclado no concreto, a quantidade de água absorvida também aumenta, isto é, o aumento de poros e condutos capilares influencia diretamente na resistência e também na durabilidade.

Segundo Kaefer (2009), a porosidade está diretamente relacionada com a resistência da pasta de concreto, pois os poros de ar, decorrentes da má vibração do concreto, reduzem a resistência do mesmo e aumentam a sua permeabilidade. Em contra partida já era esperado o aumento dos vasos capilares no concreto com agregado reciclado, pois de acordo com Ângulo (2004), os RCC apresentam materiais cerâmicos, que por sua vez, são porosos e tem a tendência de absorver mais água.

Outro fator que pode ter influenciado no aumento dos poros foi o fator água/cimento elevado usado no traço do concreto. Segundo Neville (1997) quando o fator água/cimento for maior for que 0,38 a quantidade de gel resultante da hidratação da pasta de cimento não será suficiente para preencher progressivamente os espaços inicialmente ocupados pela água. Ou seja, o fator água/cimento usado na fabricação do concreto foi consideravelmente alto, proporcionando a hidratação de todas as partículas de cimento, porém com presença de poros capilares. Já para Cabral et al, (2009), a porosidade aumenta quanto maior for a relação água/cimento, diminuindo a resistência.

\section{CONCLUSÃO}

Percebe-se que há uma preocupação contemporânea com o desenvolvimento sustentável, e isso tem sido uma alternativa ao modelo econômico vigente. A reutilização de RCC tem se mostrado uma alternativa importante, já que a partir dela advém inúmeros benefícios à sociedade e ao ecossistema.

Atualmente, na cidade de Presidente Prudente, não existe nenhum tipo de aproveitamento de RCC, sendo que este termina inevitavelmente sendo depositados em locais inapropriados.

Com objetivo de ampliar o conhecimento sobre o assunto, este trabalho trata de analisar as propriedades do concreto utilizando RCC, a partir da substituição gradual, de 40 a 100\%, do agregado reciclado.

Baseando-se nos resultados obtidos pode-se concluir que a fabricação de concreto de RCC de baixa resistência, isto é, até $20 \mathrm{MPa}$, pode 
ser realizada através da substituição parcial ou total do agregado miúdo reciclado.

Com o aumento progressivo $\mathrm{da}$ substituição do agregado reciclado, obteve-se uma redução do abatimento do concreto, uma vez que o mesmo se tornou menos trabalhável.

Este estudo verificou que o concreto reciclado apresenta resistência próxima à satisfatória, uma vez que o agregado reciclado apresenta maior absorção de água, o que implica na redução da relação $a / c$, como consequente aumento da resistência devido à elevada porosidade do agregado.

Por fim, pode-se concluir que o RCC estudado ao longo deste trabalho apresenta potencial de utilização e viabilidade econômica em vários segmentos da construção civil, tais como pavimentação de calçadas, contra piso, blocos de vedação, dentre outros.

\section{REFERÊNCIAS}

ANGULO, S.C.; et al. Caracterização de agregados de resíduos de construção e demolição reciclados separados por líquidos densos. In: Conferência Latino-Americana de Construção Sustentável Encontro Nacional de Tecnologia do Ambiente Construído. 2004.Disponível em: $<$ http://resgatebrasiliavirtual.com.br/moodle/file .php/1/E-

book/Materiais_para_Download/Construcao_Civi I/residuos_de_construcao_e_demoli_cao.pdf $>$.

Acesso em 18 de janeiro de 2017.

ASSOCIAÇÃO BRASILEIRA DE NORMAS TÉCNICAS. Argamassa e Concreto Endurecido Determinação da Absorção de Água por Capilaridade: NBR 9779, Rio de janeiro, 1995

ASSOSIAÇÃO BRASILEIRA DE NORMAS TÉCNICAS. Determinação da Consistência Pelo Abatimento do Tronco De Cone. ABNT NBR NM 67. Rio de Janeiro. 1998.

ASSOCIAÇÃO BRASILEIRA DE NORMAS TÉCNICAS. Determinação da Resistência à Compressão: NBR 5739. Rio de Janeiro, 2007.

CABRAL et al. Desempenho de concretos com agregados reciclados de cerâmica vermelha (2009). Disponivel em:<http://www.scielo.br/pdf/ce/v55n336/16.p df $>$. Acesso em: 01 de março 2017.
FREITAS JR, J. A. A estrutura do concreto. 2013. Disponível em:

http://www.dcc.ufpr.br/mediawiki/images/3/36/ TC030_Estrutinterna_x.pdf>. Acesso em: 18 de jan. 2017.

KAEFER. Considerações sobre a microestrutura do concreto. 2009. Disponível em: < http://engenhariaconcursos.com.br/arquivos/Ma teriais/microestrutura_do_concreto.pdf>. Acesso em 15 dezembro 2016.

LEITE, M. B.Avaliação de propriedades mecânicas de concretos produzidos com agregados reciclados de resíduos de construção e demolição. 2001. Dissertação (Doutorado em Engenharia civil) - Universidade Federal do Rio Grande do Sul. Disponível em: <http://www.lume.ufrgs.br/handle/10183/21839 >. Acesso 23 de janeiro 2017.

MALTA et aL.Influência da pré-saturação do agregado miúdo reciclado na viscosidade e resistência à compressão de argamassas. 2013. Disponível em: <http://www.scielo.br/scielo.php?script=sci_artt ext\&pid=S1678-86212014000100008>. Acesso em 24 de abril 2017.

MALTA, J.O. SILVA, V.S e GOLÇALVES, J.P. Argamassa contendo agregado miúdo reciclado de resíduo de construção e demolição. 2013. Disponível em: <https://portalseer.ufba.br/index.php/gesta/artic le/view/7214/6417 >. Acesso em 01 de março 2017.

NEVILLE, A. M. Propriedades do Concreto Tradução Salvador E. Giammusso

- São Paulo, 2ª edição. Pini, 1997.

ROSSIGNOLO, João A. (2009). Concreto Leve Estrutural. Produção, propriedades, microestrutura e aplicações. Disponível em: < https://pt.slideshare.net/Robimaugusto/jooadriano-rossignolo-concreto-leveestrutural?from_action=save $>$. Acesso em 02 de março 2017.

SILVA, G. R. Manual de traço de concreto. 3a edição. Rio de janeiro, 1975. 